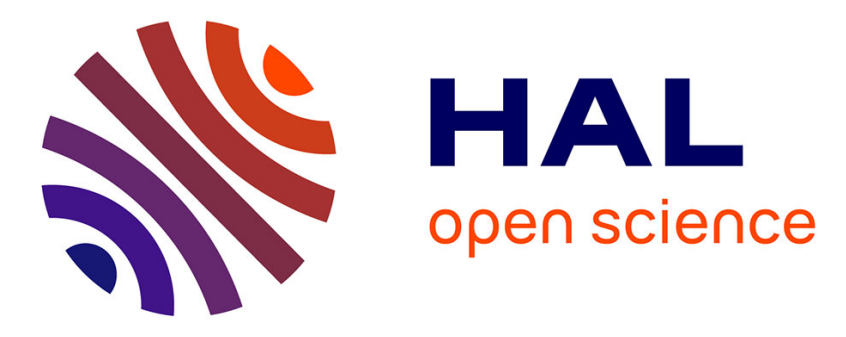

\title{
Forming mechanism of Te-based conductive-bridge memories
}

\author{
Munique Kazar Mendes, Eugenie Martinez, A Marty, Marc Veillerot, Y. \\ Yamashita, Rémy Gassilloud, M Bernard, Olivier Renault, N. Barrett
}

\section{- To cite this version:}

Munique Kazar Mendes, Eugenie Martinez, A Marty, Marc Veillerot, Y. Yamashita, et al.. Forming mechanism of Te-based conductive-bridge memories. Applied Surface Science, In press, 10.1016/j.apsusc.2017.07.187 • cea-01591636

\section{HAL Id: cea-01591636 https://hal-cea.archives-ouvertes.fr/cea-01591636}

Submitted on 21 Sep 2017

HAL is a multi-disciplinary open access archive for the deposit and dissemination of scientific research documents, whether they are published or not. The documents may come from teaching and research institutions in France or abroad, or from public or private research centers.
L'archive ouverte pluridisciplinaire HAL, est destinée au dépôt et à la diffusion de documents scientifiques de niveau recherche, publiés ou non, émanant des établissements d'enseignement et de recherche français ou étrangers, des laboratoires publics ou privés. 


\title{
Forming mechanism of Te-based conductive-bridge memories
}

\author{
M. Kazar Mendes ${ }^{a, b, *}$, E. Martinez ${ }^{a, b}$, A. Marty ${ }^{a, b}$, M. Veillerot ${ }^{a, b}$, Y. Yamashita $^{c}$, \\ R. Gassilloud ${ }^{\mathrm{a}, \mathrm{b}}$, M. Bernard ${ }^{\mathrm{a}, \mathrm{b}}$, O. Renault ${ }^{\mathrm{a}, \mathrm{b}}$, N. Barrett $^{\mathrm{d}}$ \\ a Univ Grenoble Alpes, F-38000 Grenoble, France \\ b CEA, LETI, MINATEC Campus, F-38054 Grenoble, France \\ c National Institute for Materials Science, 1-1 Namiki, Tsukuba, Ibaraki 305-0044, Japan \\ d SPEC, CEA, CNRS, Université Paris-Saclay, CEA Saclay, 91191 Gif-sur-Yvette, France
}

\section{A R T I C L E I N F O}

\section{Article history:}

Received 14 March 2017

Received in revised form 18 July 2017

Accepted 20 July 2017

Available online $\mathrm{xxx}$

\section{Keywords:}

RRAM

CBRAM

Oxygen scavenging

Interface chemistry

HAXPES

\begin{abstract}
A B S T R A C T
We investigated origins of the resistivity change during the forming of $\mathrm{ZrTe} / \mathrm{Al}_{2} \mathrm{O}_{3}$ based conductivebridge resistive random access memories. Non-destructive hard X-ray photoelectron spectroscopy was used to investigate redox processes with sufficient depth sensitivity. Results highlighted the reduction of alumina correlated to the oxidation of zirconium at the interface between the solid electrolyte and the active electrode. In addition the resistance switching caused a decrease of $\mathrm{Zr}$-Te bonds and an increase of elemental Te showing an enrichment of tellurium at the $\mathrm{ZrTe} / \mathrm{Al}_{2} \mathrm{O}_{3}$ interface. XPS depth profiling using argon clusters ion beam confirmed the oxygen diffusion towards the top electrode. A four-layer capacitor model showed an increase of both the $\mathrm{ZrO}_{2}$ and $\mathrm{AlO}_{\mathrm{x}}$ interfacial layers, confirming the redox process located at the $\mathrm{ZrTe} / \mathrm{Al}_{2} \mathrm{O}_{3}$ interface. Oxygen vacancies created in the alumina help the filament formation by acting as preferential conductive paths. This study provides a first direct evidence of the physico-chemical phenomena involved in resistive switching of such devices.
\end{abstract}

(c) 2017 Elsevier B.V. All rights reserved.

\section{Introduction}

Resistive random access memories (RRAM) are interesting candidates for the next generation of non-volatile memories (NVM). Data storage principle is based on switching the resistivity between high and low resistance states (HRS and LRS, respectively). Among them, conducting-bridge resistive random access memories (CBRAMs) are one option currently investigated, leading to promising advanced devices in terms of industrial demonstrators. The switching mechanism is based on applying voltage or current pulses to a solid electrolyte. Two types of electrolytes are currently investigated: sulphides $\left(\mathrm{GeS}_{2}\right.$ [1], $\mathrm{Cu}_{2} \mathrm{~S}$ [2], $\mathrm{Ag}_{2} \mathrm{~S}$ [3], etc.) and oxides $\left(\mathrm{Ta}_{2} \mathrm{O}_{5}\right.$ [4], $\mathrm{SiO}_{2}$ [5], $\mathrm{Al}_{2} \mathrm{O}_{3}$ [6], etc.). Ionic diffusion from the active electrode into the electrolyte creates a conductive bridge between the two electrodes. However, if the general mechanism is now well understood, more detailed information about the electrochemical processes and material changes involved in the switching is needed to optimize device design and material engineering.

\footnotetext{
* Corresponding author at: CEA, LETI, MINATEC Campus, F-38054 Grenoble, France.

E-mail addresses: Munique.KAZARMENDES@cea.fr, muniquekazar@yahoo.com.br (M.K. Mendes).
}

Historically, Ag- and Cu-based CBRAMs are the most studied [7]. The resistive switching of these devices is attributed to the formation and disruption of conductive paths between the two electrodes $[8,9]$. By applying a voltage to the device, $\mathrm{Ag}^{+}\left(\mathrm{Cu}^{+}\right)$ions from the active electrode migrate into the electrolyte. They are reduced when reaching the bottom electrode and the filament is formed by accumulation in the electrolyte. In the same way, by reversing the polarity of the applied voltage, some of the cations have returned to the active electrode and the filament is partially destroyed.

Here, we investigated subquantum CBRAMs, operating with reduced currents and thus very promising for low-power applications [10]. The current required to program a CBRAM cell is directly related to the conductance of a 1 -atom filament $\left(G_{1 \text { atom }}\right)$. Instead of using a filament containing a metal $(\mathrm{Ag}, \mathrm{Cu})$, these new memory cells are based on the diffusion of Te in the solid electrolyte. For metals $G_{1 \text { atom }}$ is comparable to the quantum $G_{0}=2 \mathrm{e}^{2} / \mathrm{h}$, whereas for a semiconductor such as $T e$, it is sub-quantum $\left(0.03 \mathrm{G}_{0}\right)$ enabling operation at low currents. The device was based on the use of a ZrTe alloy as the active electrode, which is supposed to release Te during electrical biasing. The conductive bridge of such memory cells was attributed to the migration of tellurium across the alumina [10]. Jameson at al. suggested that a possible mechanism for Te release might be the oxidation of $\mathrm{Zr}$, yielding to sub-stoichiometric alumina. Oxygen vacancies $\left(V_{O}\right)$ are thought to create preferen- 


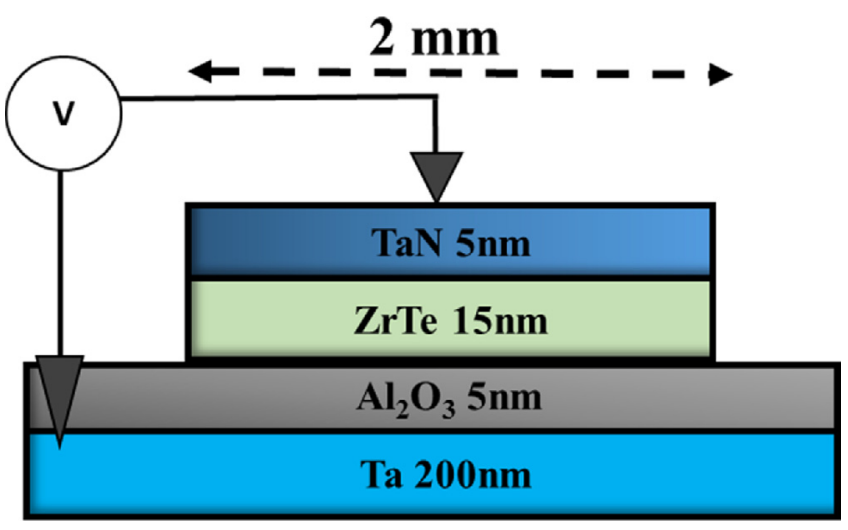

Fig. 1. Schematic of the setup for electrical characterization of the $\mathrm{TaN} / \mathrm{ZrTe} / \mathrm{Al}_{2} \mathrm{O}_{3} / \mathrm{Ta}$ stack.

tial paths for Te migration across the alumina. These assumptions were based on a detailed analysis of electrical characterizations but no direct proof has been reported yet in the literature. Here we bring information about the electrochemical mechanisms involved in resistive switching. In particular, we confirmed the key role of the $\mathrm{ZrTe} / \mathrm{Al}_{2} \mathrm{O}_{3}$ interface chemistry.

Characterizing a device is challenging because of the small amount of net change due to the filament formation. Moreover, the changes most likely occur in a thin layer buried under a thicker top electrode. This requires non-destructive characterization methods able to probe through thick capping layers with high sensitivity. The filament composition and morphology has been studied in the past using tomographic atomic force microscopy (T-AFM) [11], transmission electron microscopy (TEM) [12], and X-ray photoelectron spectroscopy (XPS) [13]. XPS profiling gives depth sensitive chemical information about cation diffusion and oxidation-reduction (redox) reactions produced during the forming process [14]. The forming process is a crucial step during which most of the chemical and structural modifications occur and which defines the final properties of the devices.

Here, we have used hard X-ray photoelectron spectroscopy (HAXPES) to probe the buried interface between the ZrTe active electrode and the $\mathrm{Al}_{2} \mathrm{O}_{3}$ layer. Measurements were performed on as-deposited samples and after $e x$-situ forming, labeled as-grown and formed. Using hard X-rays, the electron mean free path is considerably increased providing sufficient depth sensitivity to reach the buried interface and thus provide information about the redox processes occurring there. We have also used XPS depth profiling to investigate the oxygen migration.

\section{Experiment}

The memory cells were comprised of an ultrathin ( $5 \mathrm{~nm}) \mathrm{Al}_{2} \mathrm{O}_{3}$ layer sandwiched between two metallic electrodes. The bottom electrode was a $200 \mathrm{~nm}$-thick Ta layer, deposited on a $200 \mathrm{~mm} \mathrm{Si}$ (100) wafer, followed by the alumina deposition. A $15 \mathrm{~nm}$-thick ZrTe metallic alloy was deposited through a mask, to obtain $2 \mathrm{~mm}$ diameter active, top electrodes as shown in Fig. 1. These electrodes and $\mathrm{Al}_{2} \mathrm{O}_{3}$ layer were deposited by physical vapor deposition. The $\mathrm{ZrTe}$ growth process was optimized to reach a $\mathrm{Zr} / \mathrm{Te}$ stoichiometry of $40 / 60$ prior to the deposition. The base pressure in the deposition chamber was $5 \times 10^{-4}$ mbar. Finally, a 5 -nm thick TaN layer was deposited by reactive sputtering to prevent oxidation of ZrTe when exposed to air. This TaN layer is a capping layer to reproduce the operating conditions of an integrated memory stack.

Forming was performed in ambient atmosphere using a Keithley 2635B. The Ta bottom electrode was grounded. A linear positive voltage sweep between 0 and $+4 \mathrm{~V}$ was applied by an Au tip with minimum contact force on the TaN (see Fig. 1) at $0.1 \mathrm{~V} / \mathrm{s}$. Standard electrical connections cannot be used here due to the ultra-thin alumina layer which can be easily short-circuited by mechanical or thermal stress. The compliance current of $50 \mathrm{~mA}\left(0.16 \mathrm{mAcm}^{-2}\right)$ was chosen in order to avoid permanent breakdown of the oxide whilst inducing significant ionic diffusion, facilitating the detection [15].

The HAXPES experiments were performed at the BL15XU beam line of the Japan Synchrotron Radiation Research Institute (SPring8). A photon energy of $7.9 \mathrm{keV}$ with an overall energy resolution (beamline and spectrometer) of $243 \mathrm{meV}$ was employed. The inelastic mean free paths $(\lambda)$, estimated with the Tanuma equation [16] for $\mathrm{Al} 1 s, \mathrm{Zr} 3 p_{3 / 2}$ and Te $3 d_{3 / 2}$ photoelectrons in the stack, were $9.2,10.7$ and $10.4 \mathrm{~nm}$, respectively. These values are obtained by averaging the IMFPs estimated for each layer crossed by the photoelectrons during their transport toward the surface. The average was weighted by the thickness of each layer. Corresponding

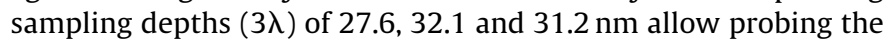
ZrTe electrode and alumina layer. The area probed by the $\mathrm{x}$-rays was $300^{*} 25 \mu \mathrm{m}^{2}$ and photoelectrons emitted at an angle of $80^{\circ}$ with respect to the surface were collected with a VG Scienta R4000 hemispherical analyzer, with a slit size of $0.5^{*} 25 \mathrm{~mm}^{2}$. The binding energy was calibrated relative to the Fermi level measured from a clean gold surface. Subtracted backgrounds for XPS spectra were of Shirley type [17], and the oxide peaks were modeled using a combination of Lorentzian (30\%) and Gaussian (70\%) functions while the metallic core lines were fitted using a Doniach-Sunjic function [18] using Casa XPS v2.3 software.

Laboratory XPS depth profiling was performed using a PHI 5000 VersaProbe II (Physical Electronics) equipped with a monochromatic $\mathrm{Al} \mathrm{K}_{\alpha}$ source $(\mathrm{h} \nu=1486.6 \mathrm{eV})$. The pass energy was set to $47 \mathrm{eV}$, giving an overall energy resolution of $0.75 \mathrm{eV}$, with an emission angle of $45.0^{\circ}$. To compensate for sample charging, in particular when analyzing the $\mathrm{Al}_{2} \mathrm{O}_{3}$ layer, a dual beam charge neutralizer was used. XPS depth profiling was carried out using an argon gas cluster ion beam (GCIB) [19] with $2500 \mathrm{Ar}$ atoms per cluster, a current of $20 \mathrm{nA}$, a raster area of $2 \mathrm{~mm}^{*} 2 \mathrm{~mm}$, ensuring uniform sputtering of the analyzed area, and $20 \mathrm{kV}$ accelerating voltage corresponding to an energy of $8 \mathrm{eV}$ per atom.

\section{Results and discussion}

\subsection{Electrical characterization}

Fig. 2(a) shows the I-V characteristic of the $\mathrm{TaN} / \mathrm{ZrTe} / \mathrm{Al}_{2} \mathrm{O}_{3} / \mathrm{Ta}$ stack measured under ambient atmosphere for the forming step. The current increases abruptly by three orders of magnitude to the $50 \mathrm{~mA}$ compliance current at high threshold voltages. This is the forming process, during which conductive paths are created through the insulating dielectric layer. It is triggered by the forming voltage $\left(V_{\mathrm{f}}\right)$, equal to $3.3 \mathrm{~V}$. The current increase at lower voltages is probably due to preliminary redox or diffusion phenomena [20].

The current limitation of $50 \mathrm{~mA}$, or compliance current, was chosen in order to generate important chemical modifications in the insulating layer or at the interfaces with the electrodes, while protecting the structure from a dielectric breakdown [15]. The device resistance measured before and after forming gave a resistance ratio $R_{\text {As-grown }} / R_{\text {Formed }}=1.10^{5}$, confirming a significant change of the devices resistivity by the formation of a conductive path (or paths) in the electrolyte. Fig. 2(b) presents a current - voltage (I-V) curve for the forming and reset processes measured on a similar memory stack. In this curve, it is possible to observe, by the application of opposite polarity, the reset operation switching the memory from the low-resistance state (LRS) to the high-resistance state (HRS) at $-1.4 \mathrm{~V}$. In this study, we focused our attention on 
(a)

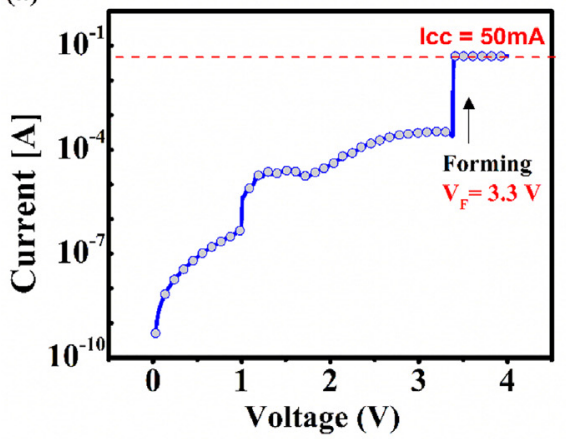

(b)

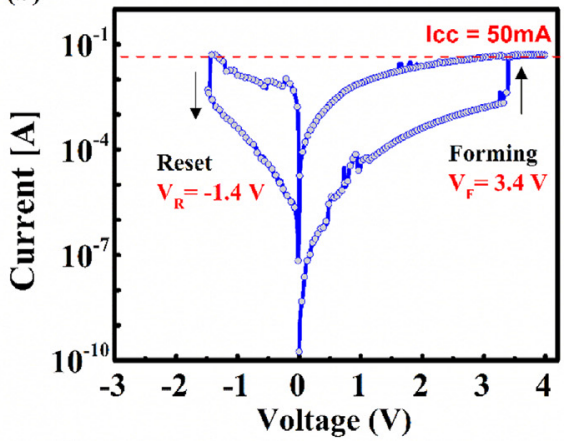

Fig. 2. (a) Current - voltage (I-V) curve for the forming of the TaN/ZrTe/Al $\mathrm{O}_{3} / \mathrm{Ta}$ stack. (b) Current - voltage (I-V) curve for the forming and reset of the TaN/ZrTe/Al $\mathrm{O}_{3} / \mathrm{Ta}$ stack.

Table 1

Relative areas (\%) of the $\mathrm{Al} 1 \mathrm{~s}$ components for the $\mathrm{Al}_{2} \mathrm{O}_{3} /$ Ta stack, as-grown and formed samples.

\begin{tabular}{lll}
\hline & $\mathrm{Al}_{2} \mathrm{O}_{3}$ & $\mathrm{AlO}_{\mathrm{x}}$ \\
\hline $\mathrm{Al}_{2} \mathrm{O}_{3} /$ Ta & $97.8 \pm 0.1$ & $2.2 \pm 0.3$ \\
$\mathrm{As}-$ grown & $91.3 \pm 0.1$ & $8.7 \pm 0.3$ \\
Formed & $88.0 \pm 0.1$ & $12.0 \pm 0.3$ \\
\hline
\end{tabular}

the critical forming step which has a key role for the device operation. HAXPES results obtained for similar devices measured after forming and reset are still under analysis and will be published in a further paper.

\subsection{Hard X-ray photoelectron spectroscopy}

HAXPES measurements were performed on as-grown and formed TaN/ZrTe $/ \mathrm{Al}_{2} \mathrm{O}_{3} /$ Ta stacks, and also on the bare $\mathrm{Al}_{2} \mathrm{O}_{3} / \mathrm{Ta}$ structure outside the top electrode (see Fig. 1), in order to provide a reference spectrum for aluminum. Each peak was normalized relative to the intensity of the background measured at high kinetic energy. The photoelectron recoil effects [21] were estimated from $E_{\text {kin }}(\mathrm{m} / \mathrm{M})$ where $\mathrm{E}_{\mathrm{kin}}$ is the photoelectron kinetic energy, $\mathrm{m}$ is the electron mass and $M$ the atomic mass. The estimation for Al $1 s$, $\mathrm{Zr} 3 p_{3 / 2}$ and Te $3 d_{3 / 2}$ core levels showed a recoil energy of 0.13 , 0.045 and $0.03 \mathrm{eV}$, respectively. Taking into account the uncertainty of $0.1 \mathrm{eV}$ on the binding energy, we have neglected these recoil energies in the rest of the paper.

The $\mathrm{Al} 1 s$ core level spectra outside the top electrode, i. e. for the $\mathrm{Al}_{2} \mathrm{O}_{3} /$ Ta stack, and for the as-grown and formed states are represented in Fig. 3 together with the best fits. The decomposition of these $\mathrm{Al} 1 \mathrm{~s}$ spectra took into account two contributions: aluminum sub-oxide (labeled $\mathrm{AlO}_{\mathrm{x}}$ ) at binding energy (BE) of $1561.5 \mathrm{eV}$ and alumina $\left(\mathrm{Al}_{2} \mathrm{O}_{3}\right)$ at $1562.4 \mathrm{eV}$. The relative areas of these components are given in Table 1.

These results showed an increase of the sub-oxide contribution $\left(\mathrm{AlO}_{\mathrm{x}}\right.$ at $\left.1561.5 \mathrm{eV}\right)$ relative to the main contribution $\left(\mathrm{Al}_{2} \mathrm{O}_{3}\right.$ at $1562.4 \mathrm{eV}$ ) for the as-grown and formed states with respect to the $\mathrm{Al}_{2} \mathrm{O}_{3}$ /Ta stack. Regarding the as-grown state, it means that the ZrTe top electrode deposition gives rise to a slight reduction of the underlying alumina layer. This phenomenon is presumably located at or near the $\mathrm{ZrTe} / \mathrm{Al}_{2} \mathrm{O}_{3}$ interface and related to oxygen scavenging by the top electrode [10]. Positively biasing this active electrode, oxygen migration, probably in the $\mathrm{O}^{2-}$ form, is enhanced leading to a further reduction of the $\mathrm{Al}_{2} \mathrm{O}_{3}$ and an increase of the $\mathrm{AlO}_{\mathrm{x}}$ contribution (+3.3\%). Oxygen migration creates positively charged $V_{O}$ in the alumina, which may have an important role in the formation of conductive filaments by acting as easy ionic diffusion paths in the solid electrolyte $[20,22,23]$.

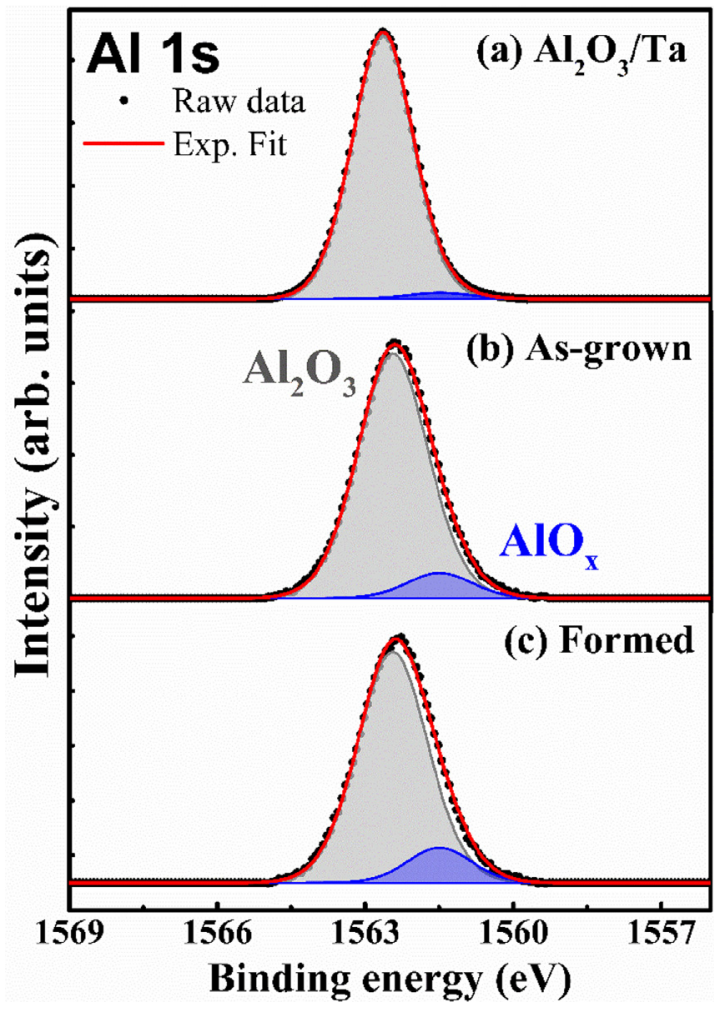

Fig. 3. Al $1 s$ core level peaks obtained by HAXPES on: a) the $\mathrm{Al}_{2} \mathrm{O}_{3} / \mathrm{Ta}$ stack, b) asgrown and $\mathrm{c}$ ) formed states of the $\mathrm{TaN} / \mathrm{ZrTe} / \mathrm{Al}_{2} \mathrm{O}_{3} / \mathrm{Ta}$ stack.

Table 2

Relative areas (\%) of the $\mathrm{Zr} 3 p_{3 / 2}$ components for the as-grown and formed samples.

\begin{tabular}{lll}
\hline & $\mathrm{ZrTe}$ & $\mathrm{ZrO}_{2}$ \\
\hline As-grown & $79.0 \pm 0.2$ & $21.0 \pm 0.4$ \\
Formed & $74.4 \pm 0.2$ & $25.6 \pm 0.4$
\end{tabular}

Fig. 4 presents the $\mathrm{Zr} 3 p_{3 / 2}$ spectra for as-grown and formed samples. The spectra have been fitted considering two contributions. The first component at $330.2 \mathrm{eV}$ was fitted using a Doniach-Sunjic [18] function and it is characteristic of the ZrTe alloy. The second component at $332.9 \mathrm{eV}$ was fitted using a Lorentzian-Gaussian function and it is characteristic of $\mathrm{ZrO}_{2}$.

Table 2 shows the relative areas of the two components of the $\mathrm{Zr} 3 p_{3 / 2}$ spectrum for as-grown and formed samples. An increase of the $\mathrm{ZrO}_{2}$ area (+4.6\%) with respect to the main peak was observed after forming, consistent with oxygen migration towards the active electrode resulting in oxidation of $\mathrm{Zr}$ at the $\mathrm{ZrTe} / \mathrm{Al}_{2} \mathrm{O}_{3}$ interface. 


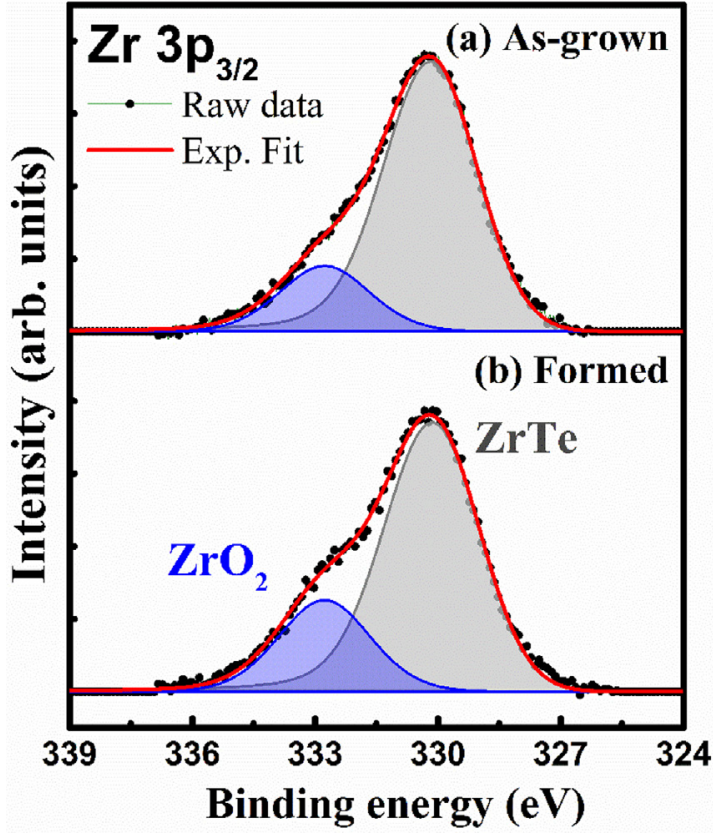

Fig. 4. $\mathrm{Zr} 3 p_{3 / 2}$ core level peaks obtained by HAXPES on: a) as-grown and b) formed states of the TaN/ZrTe/ $/ \mathrm{Al}_{2} \mathrm{O}_{3} / \mathrm{Ta}$ stack.

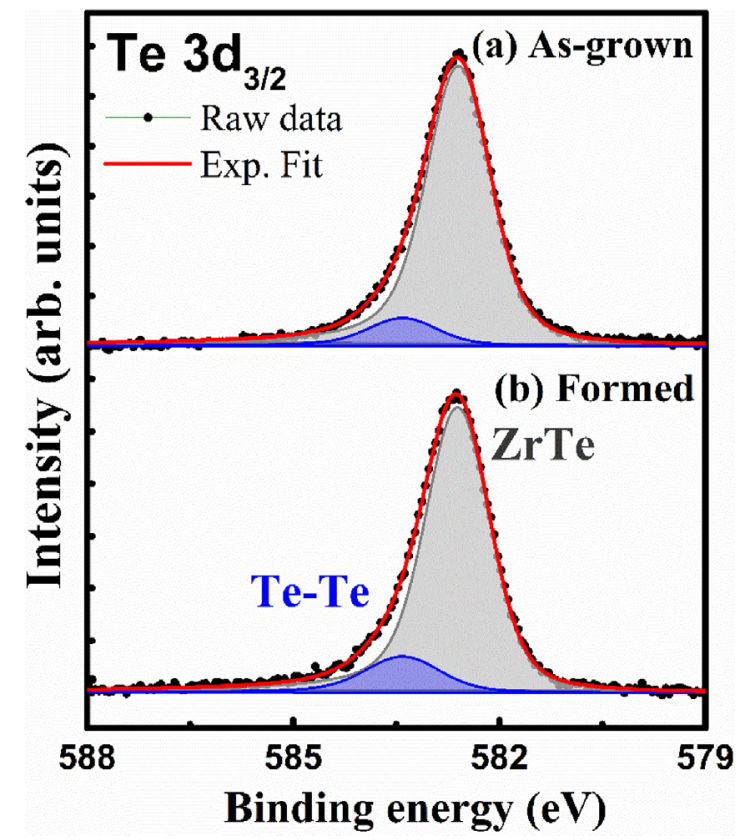

Fig. 5. Te $3 d_{3 / 2}$ core level spectra of a) as-grown and b) formed states of the $\mathrm{TaN} / \mathrm{ZrTe} / \mathrm{Al}_{2} \mathrm{O}_{3} /$ Ta stack.

The proposed mechanism for $\mathrm{Zr}$ oxidation and Te release at the interface is described by $\mathrm{ZrTe}_{\mathrm{x}}+\mathrm{O}_{2} \rightarrow \mathrm{ZrO}_{2}+\mathrm{xTe}[10]$.

The oxidation of $\mathrm{Zr}$ is thought to allow Te transport under an applied field through the oxide to create the filament. The HAXPES results provide a direct evidence of the chemistry of the first step of the proposed mechanism, i. e. Zr oxidation by oxygen scavenging from the alumina and, as a consequence, Te release.

The Te $3 d_{3 / 2}$ spectra measured for as-grown and formed samples are shown in Fig. 5. These asymmetrical peaks have been fitted using a Doniach-Sunjic function [18] by considering two contributions. The first component at $582.6 \mathrm{eV}$ is related with the ZrTe alloy
Table 3

Relative areas (\%) of the Te $3 d_{3 / 2}$ components for the as-grown and formed samples.

\begin{tabular}{lll}
\hline & ZrTe & Te-Te \\
\hline As-grown & $90.8 \pm 0.1$ & $9.7 \pm 0.4$ \\
Formed & $86.8 \pm 0.1$ & $13.2 \pm 0.3$
\end{tabular}



Fig. 6. XPS depth profiles of oxygen measured on the TiN/ZrTe $/ \mathrm{Al}_{2} \mathrm{O}_{3} / \mathrm{Ta}$ stack for as-grown and formed samples.

and the second component at $583.4 \mathrm{eV}$ is characteristic of elemental Te $[24,25]$.

Comparison between the relative areas extracted from asgrown and formed spectra is presented in Table 3. This result showed a significant elemental tellurium increase $(+3.5 \%)$ during the forming process. This increase was similar to that of the $\mathrm{ZrO}_{2}$ contribution. This result could be related to the detachment and migration of Te [10] or simply formation of Te-Te bonds inside the top electrode as a results of $\mathrm{ZrO}_{2}$ formation following oxygen uptake from the alumina.

\subsection{XPS depth profiling}

XPS depth profiling were carried out on the as-grown and formed samples to provide information about oxygen migration along the stack. The analysis was performed on a slightly different stack, with a $15 \mathrm{~nm}$-thick TiN capping layer instead of the thinner $5 \mathrm{~nm}$-thick TaN layer and a thinner $(10 \mathrm{~nm}) \mathrm{ZrTe}$ electrode.

Fig. 6 shows the XPS atomic concentration sputter depth profile of oxygen obtained from the $\mathrm{O} 1 \mathrm{~s}$ core level intensity, for the asgrown and formed samples.

The high oxygen signal before sputtering is due to surface oxidation of the TiN cap and does not influence the subsequent profiling. The onset of the buried $\mathrm{O}$ intensity obtained after forming is shifted towards the top electrode compared to the one measured for the asgrown sample. This result indicates O diffusion into the ZrTe layer which is consistent with the scavenging mechanism suggested by J. R. Jameson and al [10]. and is consistent with what is observed on the $\mathrm{Zr} \mathrm{3} p_{3 / 2}$ core level spectra, i. e. a decrease of $\mathrm{ZrTe}$ component and an increase of $\mathrm{ZrO}_{2}$.

\section{Discussion}

In the case of Te-based CBRAMs, such as $\mathrm{ZrTe} / \mathrm{Al}_{2} \mathrm{O}_{3}$ devices, our results showed that a redox process occurs at the $\mathrm{ZrTe} / \mathrm{Al}_{2} \mathrm{O}_{3}$ interface $\left(\mathrm{ZrO}_{2}\right.$ formation and $\mathrm{Al}_{2} \mathrm{O}_{3}$ reduction) yielding to a substoichiometric aluminium oxide. This behaviour can already be observed during the deposition of the top electrode on the alumina. $8.7 \%$ of $\mathrm{Al}$ was in a lower oxidation state compared to only $2.2 \%$ in the as-deposited $\mathrm{Al}_{2} \mathrm{O}_{3}$. This suggests a preliminary redox process 
(a) As-grown

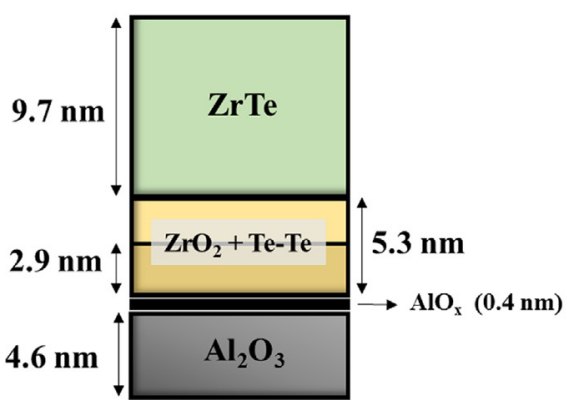

(b) Formed

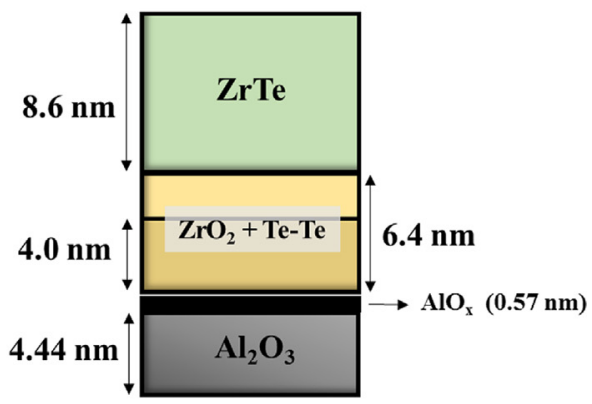

Fig. 7. Four-layer capacitor model for the (a) as-grown and (b) formed samples.

at the $\mathrm{ZrTe} / \mathrm{Al}_{2} \mathrm{O}_{3}$ interface creating $\mathrm{V}_{\mathrm{O}}$ in the alumina. Indeed, the formation of $\mathrm{ZrO}_{2}$ is thermodynamically more favourable in comparison with $\mathrm{Al}_{2} \mathrm{O}_{3}$ formation, as shown by the Ellingham diagrams [8]. $V_{O}$ facilitate the creation of low resistance paths presumably via Te diffusion inside the electrolyte, as stated by Jameson et al. [10]. The $\mathrm{V}_{\mathrm{O}}$ concentration deduced from the $\mathrm{AlO}_{\mathrm{x}}$ component increased after forming with $12 \% \mathrm{Al}$ in lower oxidation state. Furthermore the comparison between the oxygen depth profiles measured on asgrown and formed samples highlighted an oxygen migration from the electrolyte into the active electrode. Electroforming has therefore enhanced the $\mathrm{O}$ scavenging by the ZrTe electrode and, as we will see, increased the release of elemental Te.

A four-layer capacitor model [26,27] was used to quantify the redox process at the $\mathrm{ZrTe} / \mathrm{Al}_{2} \mathrm{O}_{3}$ interface. We assumed that two distinct layers of $\mathrm{ZrO}_{2}$ and $\mathrm{AlO}_{\mathrm{x}}$ were formed with sharp interfaces yielding the structure shown in Fig. 7. We also assumed that the released Te stays at the interface, and is located at the same level as the interfacial $\mathrm{ZrO}_{2}$ layer, labelled $\mathrm{ZrO}_{2}+\mathrm{Te}-\mathrm{Te}$ in Fig. 7 . This is equivalent to assuming a phase separation within the layer between $\mathrm{ZrO}_{2}$ and Te.

To calculate the respective thicknesses, we considered the photoelectron intensities from each of the $\mathrm{Al}_{2} \mathrm{O}_{3}, \mathrm{AlO}_{\mathrm{x}}, \mathrm{ZrO}_{2}$ and $\mathrm{ZrTe}$ layers, given by the areas of the corresponding components of the Al $1 s$ and $\mathrm{Zr} 3 p_{3 / 2}$ core level spectra. These intensities were defined by the following equations:

$\mathrm{I}_{\mathrm{ZrTe}}=\mathrm{I}_{\mathrm{ZrTe}}^{\infty}\left[1-\exp \left(\frac{-\mathrm{d}_{\mathrm{ZrTe}}}{\lambda_{\mathrm{Zr}}}\right)\right]$

$\mathrm{I}_{\mathrm{ZrO}_{2}}=\mathrm{I}_{\mathrm{ZrO}_{2}}^{\infty} \exp \left(\frac{-\mathrm{d}_{\mathrm{ZrTe}}}{\lambda_{\mathrm{Zr}}}\right)\left[\left[1-\exp \left(\frac{-\mathrm{d}_{\mathrm{ZrO}_{2}}}{\lambda_{\mathrm{Zr}}}\right)\right]\right.$

$\mathrm{I}_{\mathrm{AlO}}=I_{\mathrm{AlO}}^{\infty} \exp \left(\frac{-\mathrm{d}_{\mathrm{ZrTe}}}{\lambda_{\mathrm{Al}}}\right) \exp \left(\frac{-\mathrm{d}_{\mathrm{ZrO}_{2}}}{\lambda_{\mathrm{Al}}}\right)\left[1-\exp \left(\frac{-\mathrm{d}_{\mathrm{AlO}_{\mathrm{x}}}}{\lambda_{\mathrm{Al}}}\right)\right]$
From Eqs. (1) and (2), we can express the intensity ratio of the $\mathrm{ZrO}_{2}$ and $\mathrm{ZrTe}$ contributions extracted from the $\mathrm{Zr} 3 p_{3 / 2}$ core level:

$$
\frac{\mathrm{I}_{\mathrm{ZrO}_{2}}}{\mathrm{I}_{\mathrm{ZrTe}}}=\frac{I_{\mathrm{ZrO}_{2}}^{\infty}}{I_{\mathrm{ZrTe}}^{\infty}} \exp \left(\frac{-\mathrm{d}_{\mathrm{ZrTe}}}{\lambda{ }_{\mathrm{Zr}}}\right) \frac{1-\exp \left(\frac{-\mathrm{d}_{\mathrm{ZrO}_{2}}}{\lambda \mathrm{Zr}}\right)}{\left[1-\exp \left(\frac{\mathrm{d}_{\mathrm{ZrTe}}}{\lambda{ }_{\mathrm{Zr}}}\right)\right]}
$$

From Eqs. (3) and (4), we can express the intensity ratio of the $\mathrm{Al}_{2} \mathrm{O}_{3}$ and $\mathrm{AlO}_{\mathrm{x}}$ contributions extracted from the $\mathrm{Al} 1 \mathrm{~s}$ core level:

$\frac{\mathrm{I}_{\mathrm{Al}_{2} \mathrm{O}_{3}}}{\mathrm{I}_{\mathrm{AlO}_{\mathrm{x}}}}=\frac{\mathrm{I}_{\mathrm{Al}_{2} \mathrm{O}_{3}}^{\infty}}{\mathrm{I}_{\mathrm{AlO}}^{\infty}} \exp \left(\frac{-\mathrm{d}_{\mathrm{AlO}}}{\lambda_{\mathrm{Al}}}\right) \frac{1-\exp \left(\frac{-\mathrm{d}_{\mathrm{Al}_{2} \mathrm{O}_{3}}}{\lambda_{\mathrm{Al}}}\right)}{\left[1-\exp \left(\frac{-\mathrm{d}_{\mathrm{AlO}}}{\lambda_{\mathrm{Al}}}\right)\right]}$

These ratios enable to estimate the thickness of the interfacial $\mathrm{AlO}_{\mathrm{x}}$ and $\mathrm{ZrO}_{2}$ layers, given that $\mathrm{d}_{\mathrm{AlO}_{\mathrm{x}}}+\mathrm{d}_{\mathrm{Al}_{2} \mathrm{O}_{3}}=5 \mathrm{~nm}$ and $\mathrm{d}_{\mathrm{ZrO}_{2}}+\mathrm{d}_{\mathrm{ZrTe}}=15 \mathrm{~nm}$. We also assumed that the intensities of the semi-infinite blocks of the $\mathrm{Al}_{2} \mathrm{O}_{3}$ and $\mathrm{AlO}_{\mathrm{x}}$ layers were equal. The same assumption was made for the $\mathrm{ZrO}_{2}$ and $\mathrm{ZrTe}$ layers.

The thicknesses of the $\mathrm{ZrO}_{2}$ and $\mathrm{AlO}_{\mathrm{x}}$ layers calculated using this model for the as-grown and formed samples are given in Table 4 together with the intensity ratios of the $\mathrm{Al}_{2} \mathrm{O}_{3}, \mathrm{AlO}_{\mathrm{x}}, \mathrm{ZrO}_{2}$ and $\mathrm{ZrTe}$ components in the core level spectra.

Similarly, the intensity ratio between the Te and ZrTe contributions extracted from the Te $3 d_{3 / 2}$ core level can be expressed as follows:

$\frac{\mathrm{I}_{\mathrm{Te}}-\mathrm{Te}}{\mathrm{I}_{\mathrm{ZrTe}}}=\frac{\mathrm{I}_{\mathrm{Te}-\mathrm{Te}}^{\infty}}{\mathrm{I}_{\mathrm{ZrTe}}^{\infty}} \exp \left(\frac{-\mathrm{d}_{\mathrm{ZrTe}}}{\lambda_{\mathrm{Te}}}\right) \frac{1-\exp \left(\frac{-\mathrm{d}_{\mathrm{Te}-\mathrm{Te}}}{\lambda_{\mathrm{Te}}}\right)}{\left[1-\exp \left(\frac{-\mathrm{d}_{\mathrm{ZrTe}}}{\lambda_{\mathrm{Te}}}\right)\right]}$

where $\mathrm{d}_{\mathrm{Te}-\mathrm{Te}}$ is the thickness of the Te-rich layer formed near the interface and $\lambda_{\mathrm{Te}}$ is equal to $10.4 \mathrm{~nm}$. From this last equation, we calculated the thickness of the interfacial Te-rich layer to be 2.9 and $4.0 \mathrm{~nm}$, for the as-grown and formed samples respectively (see

$\mathrm{I}_{\mathrm{Al}_{2} \mathrm{O}_{3}}=\mathrm{I}_{\mathrm{Al}_{2} \mathrm{O}_{3}}^{\infty} \exp \left(\frac{-\mathrm{d}_{\mathrm{ZrTe}}}{\lambda_{\mathrm{Al}}}\right) \exp \left(\frac{-\mathrm{d}_{\mathrm{Zr}} \mathrm{O}_{2}}{\lambda_{\mathrm{Al}}}\right) \exp \left(\frac{-\mathrm{d}_{\mathrm{AlO}_{\mathrm{x}}}}{\lambda_{\mathrm{Al}}}\right)\left[1-\exp \left(\frac{-\mathrm{d}_{\mathrm{Al}_{2} \mathrm{O}_{3}}}{\lambda_{\mathrm{Al}}}\right)\right]$

where $\mathrm{d}_{\mathrm{ZrTe}}, \mathrm{d}_{\mathrm{ZrO}_{2}}, \mathrm{~d}_{\mathrm{AlO} \mathrm{x}_{\mathrm{x}}}$ and $\mathrm{d}_{\mathrm{Al}_{2} \mathrm{O}_{3}}$ are the thicknesses of the $\mathrm{ZrTe}, \mathrm{ZrO}_{2}, \mathrm{AlO}_{\mathrm{x}}$ and $\mathrm{Al}_{2} \mathrm{O}_{3}$ layers of the model. For simplicity, we assumed that the inelastic mean free paths of $\mathrm{Al} 1 s$ and $\mathrm{Zr} \mathrm{3} p_{3 / 2}$ photoelectrons were the same in all the layers of the stack and respectively equal to $\lambda_{\mathrm{Al}}=9.2 \mathrm{~nm}$ and $\lambda_{\mathrm{Zr}}=10.7 \mathrm{~nm}$. This approximation leads to an uncertainty of $\pm 1.3 \mathrm{~nm}$ in the $\mathrm{ZrO}_{2}$ layer estimation.
Table 4).

After the forming process, we saw an increase of $1.1 \mathrm{~nm}$ at the interfacial $\mathrm{ZrO}_{2}$ layer (see Fig. 7(b)). The Te-rich layer showed a similar growth. This trend agrees with the redox process deduced from the detailed analysis of the $\mathrm{Al} 1 s, \mathrm{Zr} 3 p_{3 / 2}$ and Te $3 d_{3 / 2}$ peaks. The electroforming enhances the $\mathrm{Zr}$ oxidation, releasing Te from 
Table 4


core-level components intensities.

\begin{tabular}{|c|c|c|c|c|c|c|c|}
\hline Sample & $\mathrm{I}_{\mathrm{Al}_{2} \mathrm{O}_{3}} / \mathrm{I}_{\mathrm{AlO}_{\mathrm{x}}}$ & $\mathrm{I}_{\mathrm{ZrO}_{2}} / \mathrm{I} \mathrm{ZrTe}$ & $\mathrm{I}_{\mathrm{Te}-\mathrm{Te}} / \mathrm{I}_{\mathrm{ZrTe}}$ & $\mathrm{d}_{\mathrm{AlO}_{\mathrm{x}}}(\mathrm{nm})$ & $\mathrm{d}_{\mathrm{ZrO}_{2}}(\mathrm{~nm})$ & $\mathrm{d}_{\mathrm{Te}-\mathrm{Te}}(\mathrm{nm})$ & $\mathrm{d}_{\mathrm{ZrTe}}(\mathrm{nm})$ \\
\hline As-grown & 9.0 & 0.26 & 0.11 & 0.40 & 5.3 & 2.9 & 9.7 \\
\hline Formed & 6.0 & 0.36 & 0.17 & 0.57 & 6.4 & 4.0 & 8.6 \\
\hline
\end{tabular}

the alloy. Note that the $\mathrm{ZrO}_{2}$ layer extends over nearly half of the top electrode, showing that oxygen diffuses deeply inside ZrTe. This thickness was probably overestimated due to an additional $\mathrm{ZrO}_{2}$ contribution on the $\mathrm{Zr} 3 p_{3 / 2}$ peak coming from $\mathrm{Zr}$ oxidation at the upper TaN/ZrTe interface. Indeed, the TaN capping layer did not completely prevent oxidation of ZrTe. The Te-rich layer is thinner by half compared to $\mathrm{ZrO}_{2}$. The released Te is confined near the $\mathrm{ZrTe} / \mathrm{Al}_{2} \mathrm{O}_{3}$ with a possible extension inside the alumina. A small increase of the interfacial $\mathrm{AlO}_{\mathrm{x}}$ layer was also obtained after the voltage application, confirming the creation of $\mathrm{V}_{\mathrm{O}}$ inside the alumina layer. Assuming that this is an interfacial effect, our model showed that the $\mathrm{AlO}_{\mathrm{x}}$ thickness is $0.17 \mathrm{~nm}$ higher after forming but very confined ( $\sim 2$ monolayers). However, this reduction process is probably not only located at the interface, but extends through the whole alumina layer, to achieve the formation of preferential conductive paths. Therefore, the $\mathrm{AlO}_{\mathrm{x}}$ thickness obtained with our simplified multilayer model was probably underestimated.

The electrical measurements reported by Jameson et al. [10] showed that the conductance of such CBRAMs cells is equal to 0.03 $G_{0}$, below the standard $G_{0}$ value. The switching mechanism is thus related neither to a metallic filament nor to $V_{O}$. The conductance is more consistent with a Te filament, suggesting that the presence of Te inside the oxide is directly related to the oxidation of $\mathrm{Zr}$. Our study clearly showed the correlation of $\mathrm{Zr}$ oxidation with the release of Te at the $\mathrm{ZrTe} / \mathrm{Al}_{2} \mathrm{O}_{3}$ interface. However, it is more difficult to conclude on the chemical nature of the filament. For the sake of consistency with the electrical results reported in [10], we assume that filaments are made of Te. The HAXPES Te $3 d_{3 / 2}$ spectra showed that the released $\mathrm{Te}$ is not ionized. The Te migration through the alumina is thus not directly driven by the electric field and more difficult to explain. A plausible mechanism is that: a) first Te accumulates at the interface and then progressively inside the alumina, b) second, local Te segregation might occur through $\mathrm{V}_{\mathrm{O}}$, acting as easier diffusion paths towards the bottom electrode. This study provides evidence of the physico-chemical phenomena involved during the electroforming process. However, it cannot be excluded that other concurrent physical mechanisms generate or contribute to the resistive switching.

\section{Conclusion}

We investigated subquantum CBRAMs based on the $\mathrm{ZrTe} / \mathrm{Al}_{2} \mathrm{O}_{3} / \mathrm{Ta}$ stack using HAXPES and XPS to learn about electrochemical reactions and ionic transport involved in the electroforming process. HAXPES measurements allowed in-depth analyses of the stack without degrading the original structure by sample preparation such as ion sputtering or chemical etching. This was of real interest to avoid damaging the region of interest, in particular the $\mathrm{ZrTe} / \mathrm{Al}_{2} \mathrm{O}_{3}$ interface. Results showed the oxidation of $\mathrm{Zr}$ together with a correlated alumina reduction during forming. This redox process is related to oxygen scavenging by the active top electrode. This $\mathrm{O}$ migration leads to the creation of positively charged $V_{O}$ in the alumina, thereby creating favored conductive paths. XPS depth profiling confirmed the $O$ diffusion from the $\mathrm{Al}_{2} \mathrm{O}_{3}$ towards the $\mathrm{ZrTe}$ top electrode. A four-layer capacitor model showed an increase of both the $\mathrm{ZrO}_{2}$ and $\mathrm{AlO}_{\mathrm{x}}$ interfacial layers, confirming the redox process located between the active electrode and the electrolyte. Furthermore the resistance switching caused also an elemental Te increase at the interface $\mathrm{ZrTe} / \mathrm{Al}_{2} \mathrm{O}_{3}$.

\section{References}

[1] E. Vianello, G. Molas, F. Longnos, P. Blaise, E. Souchier, C. Cagli, G. Palma, J. Guy, M. Bernard, M. Reyboz, G. Rodriguez, A. De Salvo, F. Dahmani, P. Verrier, D. Bretegnier, J. Liebault, Sb-doped GeS2 as performance and reliability booster in Conductive Bridge RAM, in: IEEE, 2012, pp. 31.5.1-31.5.4.

[2] N. Banno, T. Sakamoto, N. Iguchi, H. Sunamura, K. Terabe, T. Hasegawa, M. Aono, Diffusivity of cu ions in solid electrolyte and its effect on the performance of nanometer-scale switch, IEEE Trans. Electron Devices 55 (2008) 3283-3287.

[3] K. Terabe, T. Hasegawa, T. Nakayama, M. Aono, Quantized conductance atomic switch, Nature 433 (2005) 47-50.

[4] S. Maikap, S.Z. Rahaman, T.Y. Wu, F. Chen, M.-J. Kao, M.-J. Tsai, Low current (5 pA) resistive switching memory using high-k Ta205 solid electrolyte, in: IEEE, 2009, pp. 217-220.

[5] C. Schindler, S.C.P. Thermadam, R. Waser, M.N. Kozicki, Bipolar and unipolar resistive switching in Cu-doped SiO2, IEEE Trans. Electron Devices 54 (2007) 2762-2768.

[6] L. Goux, K. Opsomer, R. Degraeve, R. Müller, C. Detavernier, D.J. Wouters, M. Jurczak, L. Altimime, J.A. Kittl, Influence of the Cu-Te composition and microstructure on the resistive switching of Cu-Te/Al203/Si cells, Appl. Phys. Lett. 99 (2011) 053502.

[7] R. Waser, M. Aono, Nanoionics-based resistive switching memories, Nat. Mater. 6 (2007) 833-840.

[8] R. Waser, R. Dittmann, G. Staikov, K. Szot, Redox-based resistive switching memories - nanoionic mechanisms prospects, and challenges, Adv. Mater. 21 (2009) 2632-2663.

[9] S. Clima, K. Sankaran, Y.Y. Chen, A. Fantini, U. Celano, A. Belmonte, L. Zhang, L. Goux, B. Govoreanu, R. Degraeve, D.J. Wouters, M. Jurczak, W. Vandervorst, S.D. Gendt, G. Pourtois, RRAMs based on anionic and cationic switching: a short overview, Phys. Status Solidi RRL Rapid Res. Lett. 8 (2014) 501-511.

[10] J.R. Jameson, D. Kamalanathan, Subquantum conductive-bridge memory, Appl. Phys. Lett. 108 (2016) 053505.

[11] U. Celano, L. Goux, A. Belmonte, A. Schulze, K. Opsomer, C. Detavernier, O. Richard, H. Bender, M. Jurczak, W. Vandervorst, Conductive-AFM tomography for 3D filament observation in resistive switching devices, in: 2013 IEEE Int. Electron Devices Meet, 2013, pp. 21.6.1-21.6.4.

[12] Y. Yang, P. Gao, S. Gaba, T. Chang, X. Pan, W. Lu, Observation of conducting filament growth in nanoscale resistive memories, Nat. Commun. 3 (2012) 732

[13] W. Devulder, K. Opsomer, F. Seidel, A. Belmonte, R. Muller, B. De Schutter, H. Bender, W. Vandervorst, S. Van Elshocht, M. Jurczak, L. Goux, C. Detavernier, Influence of carbon alloying on the thermal stability and resistive switching behavior of copper-telluride based CBRAM cells, ACS Appl. Mater. Interfaces 5 (2013) 6984-6989.

[14] S. Tappertzhofen, I. Valov, T. Tsuruoka, T. Hasegawa, R. Waser, M. Aono, Generic relevance of counter charges for cation-based nanoscale resistive switching memories, ACS Nano 7 (2013) 6396-6402.

[15] D. Ielmini, Resistive switching memories based on metal oxides: mechanisms, reliability and scaling, Semicond. Sci. Technol. 31 (2016) 063002.

[16] QUASES software (http://www.quases.com/products/quases-imfp-tpp2m/) using the TTP-2 M formula from S. Tanuma, C.J., Powell, D.R., Penn, Calculations of electron inelastic mean free paths (IMFPS). IV. Evaluation of calculated IMFPs and of the predictive IMFP formula TPP-2 for electron energies between 50 and 2000 eV, Surf. Interface Anal. 20 (1993) 77-89.

[17] D. Briggs, M.P. Seah (Eds.), Practical Surface Analysis, Auger and X-ray Photoelectron Spectroscopy, vol. 1, edition, Wiley Chichester, New York, 1996.

[18] S. Doniach, M. Sunjic, Many-electron singularity in X-ray photoemission and X-ray line spectra from metals, J. Phys. C Solid State Phys. 3 (1970) 285

[19] I. Yamada, J. Matsuo, N. Toyoda, A. Kirkpatrick, Materials processing by gas cluster ion beams, Mater. Sci. Eng. R Rep. 34 (2001) 231-295.

[20] M. Saadi, P. Gonon, C. Vallée, C. Mannequin, H. Grampeix, E. Jalaguier, F. Jomni, A. Bsiesy, On the mechanisms of cation injection in conducting bridge memories: the case of $\mathrm{HfO} 2$ in contact with noble metal anodes ( $\mathrm{Au} \mathrm{Cu}, \mathrm{Ag}$ ), J Appl. Phys. 119 (2016) 114501

[21] Y. Takata, Y. Kayanuma, M. Yabashi, K. Tamasaku, Y. Nishino, D. Miwa, Y. Harada, K. Horiba, S. Shin, S. Tanaka, E. Ikenaga, K. Kobayashi, Y. Senba, H. Ohashi, T. Ishikawa, Recoil effects of photoelectrons in a solid, Phys. Rev. B 75 (2007) 233404.

[22] Y.-L. Chung, W.-H. Cheng, J.-S. Jeng, W.-C. Chen, S.-A. Jhan, J.-S. Chen, Joint contributions of Ag ions and oxygen vacancies to conducting filament evolution of Ag/TaOx/Pt memory device, J. Appl. Phys. 116 (2014) 164502. 
[23] G. Molas, E. Vianello, F. Dahmani, M. Barci, P. Blaise, J. Guy, A. Toffoli, M. Bernard, A. Roule, F. Pierre, C. Licitra, B.D. Salvo, L. Perniola, Controlling oxygen vacancies in doped oxide based CBRAM for improved memory performances, in: 2014 IEEE Int. Electron Devices Meet., 2014, pp. 6.1. 1-6.1.4. 3.

[24] M.K. Bahl, R.L. Watson, K.J. Irgolic, X-ray photoemission studies of tellurium and some of its compounds, J. Chem. Phys. 66 (1977) 5526-5535.

[25] H. Neumann, M. Mast, J. Enderlein, R.D. Tomlinson, M.V. Yakushev, XPS analysis of bridgman-grown CuInTe2 and of its native oxide, Cryst. Res. Technol. 31 (1996) 75-85.
[26] N. Barrett, O. Renault, J.-F. Damlencourt, F. Martin, Thermal stability of the $\mathrm{HfO} 2 / \mathrm{SiO} 2$ interface for sub-0.1 $\mu \mathrm{m}$ complementary

metal-oxide-semiconductor gate oxide stacks: a valence band and quantitative core-level study by soft x-ray photoelectron spectroscopy, J. Appl. Phys. 96 (2004) 6362-6369.

[27] A. Jablonski, J. Zemek, Overlayer thickness determination by XPS using the multiline approach, Surf. Interface Anal. 41 (2009) 193-204.

Please cite this article in press as: M.K. Mendes, et al., Forming mechanism of Te-based conductive-bridge memories, Appl. Surf. Sci. (2017), http://dx.doi.org/10.1016/j.apsusc.2017.07.187 